tụt huyết áp trong lúc thực hiện thủ thuật.

\section{KẾT LUẬN}

Phương pháp đặt nội khí quản nhanh theo trình tự với ketamine và rocuronium áp dụng với những bệnh nhân cấp cứu không có yếu tố tiên lượng đường thở khó làm giảm thời gian thực hiện thủ thuật, tăng tỷ lệ thành công trong lẩn đặt đâu tiên và không làm tăng nguy cơ các biến cổ nghiêm trọng trong quá trình thực hiện so với những bệnh nhân đặt nội khí quản không dùng giãn cơ.

\section{TÀI LIÊU THAM KHẢO}

1. Mace SE, Ducharme J, Murphy MF, eds. Pain Management and Sedation: Emergency Department Management. New York: McGraw-Hill, Medical Pub. Division; 2006.

2. Reed MJ. Can an airway assessment score predict difficulty at intubation in the emergency department? Emergency Medicine Journal.
2005;22(2):99-102

3. Yamanaka S, Goldman RD, Goto T, Hayashi H. Multiple intubation attempts in the emergency department and in-hospital mortality: A retrospective observational study. Am J Emerg Med. 2020;38(4):768-773.

4. On behalf of the Japanese Emergency Medicine Network Investigators, Okubo M, Gibo K, Hagiwara Y, Nakayama Y, Hasegawa K. The effectiveness of rapid sequence intubation (RSI) versus non-RSI in emergency department: an analysis of multicenter prospective observational study. Int J Emerg Med. 2017;10(1):1.

5. Kerslake D, Oglesby AJ, Di Rollo N, James E, McKeown DW, Ray DC. Tracheal intubation in an urban emergency department in Scotland: A prospective, observational study of 3738 intubations. Resuscitation. 2015;89:20-24.

6. Driver $B E$, Prekker ME, Reardon RF, et al. Success and Complications of the Ketamine-Only Intubation Method in the Emergency Department. The Journal of Emergency Medicine. 2021;60(3):265-272.

\title{
TRẦM CẢM THEO THANG DASS 21 Ở SINH VIÊN HỆ BÁC SĨ Y KHOA NĂM THỨ NHẤT TRƯỜNG ĐAI HỌC Y HÀ NộI NĂM HỌC 2020-2021 VÀ MộT SỔ YẾU TỐ LIÊN QUAN
}

\section{Lê Thị Vũ Huyền*}

\section{TÓM TẮT}

Nghiên cứu nhằm xác định tỷ lệ nguy cơ trâm cảm và một số yếu tố liên quan đến trẩm cảm ở sinh viên năm thứ nhất hệ bác sĩ y khoa trường Đại học $Y$ Hà Nội năm học 2020-2021. Nghiên cứu mô tả cắt ngang trên 345 sinh viên, công cụ để đánh giá trầm cảm là thang DASS 21 . Kết quả cho thấy $52,8 \% \%$ sinh viên có nguy cơ mắc trầm cảm. Trong đó trầm mức độ nhe: $20,6 \%$, trầm cảm mức độ vừa: $18,6 \%$, trầm cảm mức độ nặng: 6,7\%, rất nặng: 7,0\%. Các yếu tố liên quan đến nguy cơ trầm cảm ở sinh viên năm thứ nhất hệ bác sĩ Y khoa là: không hài lòng với ngoai hình, khó khăn với tài chính, tập thể dục, xung đột với bạn cùng phòng, giảm sức khỏe bản thân, chấn thướng ốm nă̆ng, một thành viên trong gia đình bị bệnh nặng, điểm học không như mong đợi, thích nghi với việc học ở trường đại học

\section{SUMMARY \\ DEPRESSION ASSESSED BY DASS 21 SCALE AMONG FIRST YEAR MEDICAL DOCTOR STUDENTS AT HANOI MEDICAL}

\footnotetext{
*Trường Đại học Y Hà Nội

Chịu trách nhiệm chính: Lê Thị Vũ Huyền

Email: levuhuyen@hmu.edu.vn

Ngày nhận bài: 16.9.2021

Ngày phản biên khoa họ: 15.11.2021

Ngày duyệt bài: 23.11.2021
}

\section{UNIVERSITY IN THE 2020-2021 ACADEMIC} YEAR AND SOME ASSOCIATED FACTORS

The study aimed to determine the proportion of students experiencing depression and some factors related to depression among first-year medical doctor students at Hanoi Medical University in the academic year 2020-2021. We conducted a cross-sectional study on 345 students and used the DASS 21 scale to assess the level of depression among students. Our results showed that $52,8 \%$ of students had depression (20.6\% with mild depression, $18.6 \%$ with moderate depression, $6.7 \%$ with severe depression, $7.0 \%$ with very severe depression). Factors associated with depression among first-year medical students included dissatisfaction with appearance,financial difficulties, exercise, conflicts with roommates, reduced selfhealth, serious illness injury, a serious illness in the family, poor grades wait, adjust to studying at university

Tư khóa: Trầm cảm, sinh viên năm thứ nhất hệ Bác sĩ Y khoa, yếu tố liên quan

\section{I. ĐẶT VẤN ĐỀ}

Trầm cảm là một bệnh tâm thần đặc trưng bởi tâm trạng buồn chán và giảm hứng thú hoặc niềm vui trong việc thực hiện các hoạt động hàng ngày. ${ }^{1}$ Căn bệnh này là một trong những nguyên nhân chính gây ra tàn tật trên thế giới, ảnh hưởng đến gần 300 triệu người ở mọi lứa 
tuổi, Trầm cảm cũng là một yếu tố nguy cơ quan trọng đối với tự tử, cướp đi hàng trăm ngàn sinh mạng mỗi năm. ${ }^{2}$ Tỷ lệ mắc bệnh ở những người từ 18 đến 29 tuổi cao gấp ba lần so với những người trên 60 tuổi. ${ }^{1}$ Giáo dục y tế là một trong những lĩnh vực cạnh tranh nhất, tạo ra căng thẳng cao độ trong sinh viên, gây hại cho quá trình học tập, sức khỏe tinh thần và thể chất của sinh viên. ${ }^{3}$

Sinh viên năm thứ nhất bắt đầu bước vào ngưỡng cửa trường đại học, việc thay đổi môi trường sống, phương pháp học tập ở đại học và học tập trong một môi trường đầy áp lực như trường đại học $Y$ Hà Nội cũng là những thách thức đối với các em. Nguy cơ trầm cảm mà các em gặp phải ra sao, yếu tố nào là yếu tố làm tăng nguy cơ trầm cảm là một vấn đề lớn cần phải quan tâm. Hiện nay, hệ bác sĩ Y khoa chương trình đang thay đổi do đó việc tìm hiểu stress trên sinh viên hệ bác sĩ Y khoa năm thứ nhất và các yếu tố liên quan sẽ là cơ sở cho việc xây dựng được chương trình học tập, các biện pháp hỗ trợ sinh viên trên cơ sở đó giúp hạn chế hậu quả tiêu cực do trầm cảm gây nên. Với những lý do trên chúng tôi tiến hành nghiên cứu đề tài: "Trầm cảm theo thang DASS 21 ở sinh viên hệ bác sĩ Y khoa năm thứ nhất trường đại hoc Y Hà Nội năm học 2020-2021 và một số yếu tố liên quan"với 2 mục tiêu cụ thể sau:

1. Mô tả thực trạng nguy cơ trầm cảm của sinh viên hệ bác sĩ y khoa năm thứ nhất trường Đai hoc Y Hà Nôi năm hoc 2020-2021.

2. Phân tích một số yêu tố liên quan đến nguy cơ trầm cảm của sinh hê bác sĩ y khoa năm thứ nhất trường Đại học Y Hà Nội năm học 20202021.

\section{II. ĐỐI TƯợNG VÀ PHƯƠNG PHÁP NGHIÊN CỨU 1. Đối tượng nghiên cứu:}

*Tiêu chuẩn lựa chọn:

- Sinh viên hê bác sỹ̃ Y khoa năm thứ nhất Trường Đại học Y Hà Nội năm học 2020-2021.

- Sinh viên đồng ý tham gia vào nghiên cứu.

* Tiêu chuẩn loại trừ:

- Sinh viên không hợp tác tham gia nghiên cứu.

- Sinh viên không có mặt trong thời gian nghiên cứu.

*Thời gian nghiên cứu:

- Thời gian nghiên cứu: Từ tháng 10/2020 đến tháng 06/2021.

- Thời gian thu thập số liệu: Từ tháng 03/2021 đến tháng 04/2021.

\section{Phương pháp nghiên cứu Thiết kế nghiên cứu:}

Thiết kế nghiên cứu: Mô tả cắt ngang.

Cỡ mẫu và cách chọn mẫu. Nghiên cứu đã lấy toàn bộ sinh viên năm thứ nhất ngành bác sỹ $Y$ khoa trường đại học $Y$ Hà Nội. Trên thực tế sau khi đã loại đi một số phiếu sót thông tin hoặc một số sinh viên từ chối không tham gia nghiên cứu, cõ̃ mẫu cuối cùng là 345 sinh viên

\section{Các biến số nghiên cứu}

Các biến số về thông tin chung của đối tượng nghiên cứu

- Giới tính, điểm trung bình học tập

Các biến số cho mục tiêu 1: Tỷ lệ trầm cảm của sinh viên

Các biến số và chỉ số cho mục tiêu 2

- Yếu tố cá nhân: giới, hài lòng với ngoại hình, có bạn thân, chia sẻ với bạn thân, đi làm thêm, khó khăn về tài chính, nợ tiền, tập thể dục, giảm sức khỏe bản thân hoặc bị chấn thương

- Yếu tố gia đình: tình trạng hôn nhân của bố mẹ, xung đột với bố me, một thành viên trong gia đình bị bệnh nặng

- Yếu tố nhà trường: xung đột với bạn cùng phòng, gia tăng việc học ở trường, điểm trung bình học tập, điểm học không như mong đợi, thích nghi với phương pháp học ở đại học, nợ môn.

Phương pháp thu thập thông tin:

- Điều tra viên được tập huấn kỹ về kĩ năng, nội dung công việc.

- Điều tra viên liên hệ phòng Đào tạo Đại học để xem lịch học của đối tượng nghiên cứu. Trển cơ sở lịch học, chọn thời điểm phù hợp nhất với đối tượng nghiên cứu để ít ảnh hưởng đến thời gian học tập của đối tượng nghiên cứu.

\section{Công cụ thu thập số liệu}

Bộ câu hỏi nghiên cứu bao gồm 3 phần:

Phần 1: Thông tin chung của đối tượng

Phần 2: Thang DASS 21 (Depression Anxiety Stress Scale 21) gồm 21 câu hỏi đánh giá trâm cảm- lo âu- stress. Trong nghiên cứu này chủ yếu tập trung đánh giá trầm cảm nên dựa vào tổng điểm của các câu hỏi thành phần gồm các câu $3,5,10,13,16,17,21$ rồi nhân hệ số 2 . Sau khi có kết quả thì đánh giá trầm cảm dựa trên 5 mức độ: bình thường (0-9), nhe (10-13), vừa (14-20), nặng (21-27), rất nặng ( $\geq 28)$

Phần 3: Các câu hỏi về những thông tin liên quan đến những yếu tố cá nhân, gia đình và nhà trường

Xử lý số liệu. Số liệu sau khi được làm sạch và được nhập vào Excel và phân tích bằng phần mềm SPSS 20. Nghiên cứu sử dụng phân tích đơn biến để xác định yếu tố liên quan đến stress trên sinh viên năm thứ nhất

3. Đạo đức nghiên cứu: Nghiên cứu được 
tiến hành với sự đồng ý của phòng Đào tạo Đại học, Viện đào tạo $Y$ học dự phòng và $Y$ tể công cộng, Bộ môn Y đức và tầm lý học Trường Đại học $Y$ Hà Nội.

Đối tượng nghiên cứu được cung cấp đầy đủ thông tin về mục đích, nội dung của nghiên cứu, tự nguyên tham gia bằng cách xác nhận vào bản thỏa thuận tham gia nghiên cứu, thông tin của đối tượng tham gia nghiên cứu hoàn toàn được giữ bí mật. Nễu đối tượng từ chối hoặc ngưng giữa chừng thì không bắt ép đối tượng tham gia nghiên cứu

\section{KẾT QUẢ NGHIÊN CỨU}

\section{1. Đặc điểm chung về đôi tượng nghiên cứu \\ Bảng 1. Một số thông tin chung về đôî} tượng nghiên cứu

\begin{tabular}{|c|c|c|c|}
\hline \multicolumn{2}{|c|}{ Đặc điểm chung } & Số lượng & Tỷ lệ \% \\
\hline \multirow{2}{*}{ Giới } & Nam & 187 & 54,2 \\
\cline { 2 - 4 } & Nữ & 158 & 45,8 \\
\hline \multirow{3}{*}{$\begin{array}{c}\text { Học } \\
\text { lực }\end{array}$} & Giỏi & 24 & 7,0 \\
\cline { 2 - 4 } & Khá & 190 & 55,1 \\
\cline { 2 - 4 } & Trung bình & 94 & 27,2 \\
\cline { 2 - 4 } & Dưới trung bình & 12 & 3,5 \\
\hline $\mathrm{n}$ & & 345 & \\
\hline
\end{tabular}

Sinh viên nam nhiều hơn sinh viên nữ chiếm tỷ lệ $54,2 \%$. Học lực của sinh viên tính theo quy chế đào tạo tín chỉ sinh viên đạt học lực loại khá chiếm đa số với tỷ lệ $55,1 \%$, vẫn còn $3,5 \%$ đạt học lực dưới trung bình

2. Thực trạng nguy cơ trâm cảm ở sinh viên hệ bác sĩ Y khoa năm thứ nhất

Bảng 1. Thức trạng nguy cơ trâm cảm của sinh viên hệ bác sĩ $Y$ khoa năm thứ nhất

\begin{tabular}{|c|c|c|}
\hline & $\mathbf{n}$ & $\%$ \\
\hline Trầm cảm & 182 & 52,8 \\
\hline Không trầm cảm & 163 & 47,2 \\
\hline \multicolumn{3}{|c|}{ Các mức độ trâm cảm } \\
\hline Trầm cảm mức độ nhẹ & 71 & 20,6 \\
\hline Trầm cảm mức độ vừa & 64 & 18,6 \\
\hline Trâm cảm mức độ nặng & 23 & 6,7 \\
\hline Trầm cảm mức độ rất nặng & 24 & 7,0 \\
\hline $\mathrm{n}$ & 345 & 100 \\
\hline
\end{tabular}

Tỷ lệ sinh viên có nguy cơ trâm cảm là $52,8 \%$. Trong đó mức độ nhe và vừa là chủ yếu chiếm tỷ lê $20,6 \%$ và $18,6 \%$. Tỷ lê sinh viên có nguy cơ trầm cảm nặng chiếm $6,7 \%$ và rất nặng chiếm 7,0\%.

2. Một số yếu tố liên quan đến nguy cơ trâm cảm của sinh viên hệ bác sĩ Y khoa năm thứ nhất

Bảng 2. Một số yêu tố liên quan đến nguy cơ tràm cảm của sinh viên

\begin{tabular}{|c|c|c|c|c|}
\hline \multicolumn{2}{|c|}{ Các yếu tố liên quan } & Có n(\%) & Không n(\%) & OR \\
\hline \multicolumn{5}{|c|}{ Yếu tố cá nhân } \\
\hline \multirow{2}{*}{ Giới tính } & Nam & $100(53,5)$ & $87(46,5)$ & $1,07(0,70-1,63)$ \\
\hline & Nữ & $82(51,9)$ & $76(48,10$ & 1 \\
\hline \multirow{2}{*}{ Hài lòng với ngoại hình } & Không & $142(58,2)$ & $102(41,8)$ & $2,12(1,32-3,41)$ \\
\hline & Có & $40(39,6)$ & $61(60,4)$ & 1 \\
\hline \multirow{2}{*}{ Có bạn thân } & Không & $27(61,4)$ & $17(38,6)$ & $1,50(0,78-2,86)$ \\
\hline & Có & $155(51,5)$ & $146(48,5)$ & 1 \\
\hline \multirow{2}{*}{ Chia sẻ với bạn thân } & Không & $59(59,0)$ & $41(41,0)$ & $1,43(0,89-2,29)$ \\
\hline & Có & $123(50,2)$ & $122(49,8)$ & 1 \\
\hline \multirow{2}{*}{ Đi làm thêm } & Có & $49(56,3)$ & $38(43,7)$ & $1,21(0,74-1,98)$ \\
\hline & Không & $133(51,6)$ & $125(48,4)$ & 1 \\
\hline \multirow{2}{*}{ Khó khăn về tài chính } & Có & $59(61,5)$ & $37(38,5)$ & $1,63(1,01-2,64)$ \\
\hline & Không & $123(49,4)$ & $126(50,6)$ & 1 \\
\hline \multirow{2}{*}{ Tập thể dục } & Không & $73(60,8)$ & $47(39,2)$ & $1,65(1,05-2,59)$ \\
\hline & Có & $109(48,4)$ & $116(51,6)$ & 1 \\
\hline \multirow{2}{*}{$\begin{array}{l}\text { Giảm sức khỏe bản thân, } \\
\text { chấn thương ốm nặng }\end{array}$} & Có & $57(64,4)$ & $32(36,0)$ & $1,87(1,14-3,70)$ \\
\hline & Không & $125(48,8)$ & $131(51,2)$ & 1 \\
\hline \multicolumn{5}{|c|}{ Yếu tố gia đình } \\
\hline \multirow[b]{2}{*}{ Hôn nhân của bố mẹ } & Li dị/li thân/góa & $173(52,1)$ & $159(47,9)$ & $0,82(0,82-3,70)$ \\
\hline & $\begin{array}{l}\text { Đang sống } \\
\text { cùng nhau }\end{array}$ & $4(75,1)$ & $3(42,9)$ & 1 \\
\hline \multirow{2}{*}{ Mâu thuẫn với bố mẹ } & Có & $16(66,7)$ & $8(33,3)$ & $1,87(0,78-4,49)$ \\
\hline & Không & $166(51,7)$ & $155(48,3)$ & 1 \\
\hline \multirow{2}{*}{$\begin{array}{l}\text { Một thành viên trong } \\
\text { gia đình bị bệnh nặng }\end{array}$} & Có & $24(72,7)$ & $9(27,3)$ & $2,60(1,17-5,77)$ \\
\hline & Không & $158(50,6)$ & $154(49,4)$ & 1 \\
\hline
\end{tabular}


VIETNAM MEDICAL JOURNAL N²2 - DECEMBER - 2021

\begin{tabular}{|c|c|c|c|c|}
\hline \multirow{5}{*}{ Yếu tố trường học } \\
\hline \multirow{2}{*}{$\begin{array}{c}\text { Xung đột với bạn } \\
\text { cùng phòng }\end{array}$} & Có & $34(68,0)$ & $16(32,0)$ & $2,11(1,12-3,99)$ \\
\cline { 2 - 5 } & Không & $148(50,2)$ & $147(49,8)$ & 1 \\
\hline \multirow{2}{*}{$\begin{array}{c}\text { Tiểm học không như } \\
\text { mong đợi }\end{array}$} & Không & $159(57,6)$ & $117(42,4)$ & $2,72(1,56-4,73)$ \\
\cline { 2 - 5 } & Có & $23(33,3)$ & $46(66,7)$ & 1 \\
\hline \multirow{3}{*}{ Điểm TB học tập } & ĐTB $<7,0$ & $70(55,6)$ & $56(44,4)$ & $1,14(0,65-2,01)$ \\
\cline { 2 - 5 } & $7,0 \leq Đ T B<8,0$ & $65(46,8)$ & $74(53,2)$ & $1,62(0,93-2,83)$ \\
\cline { 2 - 5 } & $8,0 \leq$ ĐTB & $47(58,8)$ & $33(41,2)$ & 1 \\
\hline \multirow{2}{*}{ Thích nghi việc học ở trường } & Không & $108(65,1)$ & $58(34,9 \%)$ & $2,64(1,71-4,09)$ \\
\cline { 2 - 5 } & Có & $74(41,3)$ & $105(58,7)$ & 1 \\
\hline
\end{tabular}

Yếu tố bản thân. Sinh viên không hài lòng về ngoại hình của bản thân là yếu tố nguy cơ làm tăng 2,12 (CI:1,32-3,41) lần tỷ lệ trầm cảm. Những sinh viên có khó khăn về tài chính có nguy cơ trầm cảm cao gấp $1,63(1,01-2,64)$ sinh viên khác. Sinh viên không thường xuyên tập thể dục ít nhất 30 phút/lần có nguy cơ trầm cảm cao gấp 1,65 (1,05-2,59) sinh viên có tập thể dục. Sinh viên có suy giảm sức khỏe bản thân chấn thương hoặc ốm nặng có nguy cơ trầm cảm cao gấp 1,87 $(1,14-3,70)$ sinh viên không gặp vấn đề về sức khỏe

Yếu tố gia đình. Sinh viên trong gia đình có người bị bệnh nặng có nguy cơ trâm cảm cao gấp $2,60(1,17-5,77)$ các sinh viên khác. Tình trạng hôn nhân của bố mẹ, xung đột với bố mẹ không liên quan đến nguy cơ trầm cảm của sinh viên năm thứ nhất

Yếu tố trường học. Sinh viên có xung đột với bạn cùng phòng có nguy cơ trầm cảm cao gấp 2,11 $(1,12-3,99)$ sinh viên không có xung đột với bạn cùng phòng. Sinh viên có điểm học tập không như mong đợi có nguy cơ trầm cảm cao gấp $2,72(1,56-4,73)$ sinh viên có điểm học như mong đợi. Chưa thích nghi với việc học ở trường đại học là yếu tố nguy cơ của trầm cảm trên sinh viên năm thứ nhất. Cụ thể những sinh viên chưa thích nghi với việc học ở trường đại học có nguy cơ trầm cảm cao gấp 2,72 (1,56$4,73)$ sinh viên đã thích nghi với việc học ở trường. Điểm trung bình học tập chưa phải là yếu tố nguy cơ của trầm cảm trên sinh viên năm thứ nhất

\section{BÀN LUẬN}

1. Tỷ lệ sinh viên có nguy cơ trâm cảm: Tỷ lệ sinh viên có nguy cơ trầm cảm trong nghiển cứu của chúng tôi là $52,8 \%$. Tuy nhiên chủ yếu là nguy cơ trầm cảm ở mức độ nhẹ và vừa lần lượt là: 20,6 và $18,6 \%$ chỉ có $6,9 \%$ là nặng và $7 \%$ rất nặng. Tỷ lệ sinh viên có nguy cơ trầm cảm trong nghiên cứu của chúng tôi cao hơn kết quả nghiên cứu của Nguyễn Hoàng
Nguyên cùng sử dụng thang DASS 21 (tỷ lệ trâm cảm $49,7 \%$ ) trên sinh viên hệ bác sĩ của trường đại học Y Hà Nội năm học 2018-2019. ${ }^{4}$ và nghiên cứu trên sinh viên $Y$ năm thứ nhất tại Nepal năm 2021 bằng thang DASS 42 (tỷ lệ trâm cảm ở sinh viên là $44 \%{ }^{3}$ ). Các nghiên cứu khác như: Đỗ Dinh Quyên trên sinh viên năm thứ nhất trường Đai học $Y$ dược thành phố Hồ Chí Minh năm 2008 đo trầm cảm bằng thang đo CES- $D$ tỷ lệ TC 39,6.5; Nguyễn Thị Bích Liên sử dụng thang CES-D tỷ lệ trầm cảm là 47,6 nghiên cứu trên sinh viên môt số khối sinh viên hê bác sĩ đa khoa trường đại học Y Hà Nội năm 2010-2011. ${ }^{6}$ Đặc biệt Phạm Tùng lại cho kết quả rất khác: 15,2\% sinh viên có trầm cảm khi sử dụng thang PHQ9 trên sinh viên Y khoa tại trường Đại học Y Hà Nội có trải nghiệm lâm sàng. ${ }^{7}$

Sự khác nhau này theo chúng tôi là do thang DASS 21, 42 hoặc CES-D chủ yếu để sàng lọc nên nghiên cứu sử dụng những thang này thường cho tỷ lệ trầm cảm cao còn Phạm Tùng sử dụng thang đo khác với chúng tôi (thang PHQ9). Một yếu tố làm cho kết quả của chúng tôi cao hớn những nghiên cứu có sử dụng cùng thang DASS là các nghiên cứu tiến hành ở các thời gian khác nhau và địa điểm nghiên cứu khác nhau. Nghiên cứu của chúng tôi tiến hành đúng thời điểm vừa hết dãn cách xã hội do dịch covid các em mới đi học lại còn chủ yếu học online mối quan hệ xã hội bị thu hẹp nên có thể có ảnh hưởng tới sức khỏe tinh thần nói chung và trầm cảm nói riêng cho các em. Điều này cũng có thể làm tăng tỷ lệ trầm cảm cao hơn điều kiện bình thường.

Một số yếu tố liên quan đến nguy cơ trâm cảm ở sinh viên năm thứ nhất:

Yếu tố cá nhân. Kết quả nghiên cứu của chúng tôi cho thấy không hài lòng với ngoại hình có liên quan đến nguy cơ trầm cảm. Nghiển cứu của LC Soares còn phân tích sâu hơn về hình ảnh bản thân và trầm cảm cho thấy không hải lòng về hình ảnh của bản thân vì béo phì có liên quan đến triệu chứng của trầm cảm nhưng không hài 
lòng về hình ảnh bản thân do gầy thì không liên quan đến triệu chứng trầm cảm. ${ }^{8}$

Tập thể dục được coi là yếu tố bảo vệ của trầm cảm. Kết quả cho thấy những sinh viên không tập thể dục thường xuyên có nguy cơ trầm cảm hơn sinh viên có tập thể dục. Đố Dinh Quyên cũng cho rằng tập thể dục có liên quan đến trầm cảm. ${ }^{5}$

Giảm sức khỏe bản thân chấn thương hoặc ốm nặng là yếu tố nguy cơ làm tăng nguy cơ trầm cảm trên sinh viên năm thứ nhất kết quả giống với nghiên cứu của Nguyễn Thị Bích Liên. Giảm sức khỏe bản thân làm tăng 1,6 lần so với sinh viên khỏe mạnh. Yếu tố sức khỏe đối với sinh viên $Y$ rất quan trọng một là do đây là các bạn đang học trong trường $Y$ yếu tố thứ hai là lịch học rất dày khối lượng kiến thức nhiều nếu không đảm bảo sức khỏe thì sẽ có nhiêu khó khăn trong việc đuổi kịp các bạn trong lớp và theo đước chương trình và điều này vô hình chung lại ảnh hưởng tới sức khỏe tinh thần của các em.

Khó khăn về tài chính là yễu tố làm tăng nguy cơ trầm cảm của sinh viên là kết quả nghiên cứu của chúng tôi. Phạm Tùng và các cộng sự của mình cũng đưa ra kết luận tương tự nhưng trên khối sinh viên đã có trải nghiệm lâm sàng. Như vậy kinh tế cũng là một vấn đề rất quan trọng đối với sinh viên $Y$ nói chung và sinh viên $Y$ năm thứ nhất nói riêng

Yếu tố gia đình. Nguyễn Thị Bích Liên với nghiên cứu của mình đưa ra kết luận xung đột với người thân làm tăng nguy cơ trầm cảm của sinh viên khối 2-4-6 lên 1,5 lần nhưng trong nghiên cứu của chúng tôi thì xung đột với người thân trong gia đình không phải là nguy cơ làm tăng trầm cảm trên sinh viên năm thứ nhất. Cũng có thể, xung đột có gây căng thẳng cho sinh viên nhưng chưa tới mức có là yếu tố nguy cơ của trầm cảm bởi vì sinh viên năm thứ nhất vừa đỗ vào đại học $Y$ Hà Nội là niềm tự hào của bản thân cả gia đình. Đây là một sự kiện rất lớn đánh dấu kết quả nỗ lực cố gắng của cá nhân và gia đình suốt 12 năm. Vào đại học có nhiêu thay đổi so với phổ thông có nhiều thứ cùng một lúc tác động đên các em nên cũng có thể xung đột với người thân chưa nổi bật lên là yếu tố làm tăng trầm cảm ở sinh viên $Y$ năm thứ nhất năm 2020-2021. Ngoài ra nghiên cứu của chúng tôi còn cho thấy Gia đình có người ốm nặng là nguy cơ làm tăng nguy cơ trầm cảm trên sinh viên năm thứ nhất.

Yếu tố trường học: Bước vào ngưỡng cửa trường đại học là một bước ngoặt lớn trong đời của lứa tuổi thanh niên. Bạn bè đến từ nhiều vùng miền khác nhau có những thói quen cách sống khác nhau, sống xa nhà, môi trường học tập các thây cô, môn học và đặc biệt phương pháp học tập khác hẳn ở phổ thổng. Những vấn đề liên quan đến nhà trường mà chúng tôi tìm thấy là nguy cơ làm tăng trầm cảm của sinh viên năm thứ nhất là: kết quả học tập không như mong đợi, xung đột với bạn cùng phòng, chưa thích nghi được với việc học đại học.

\section{KẾT LUÂN}

Tỷ lê sinh viên năm thứ nhất hê bác sĩ Y khoa có nguy cơ trầm cảm là $52,8 \%$. Trong đó mức độ nặng và rất nặng chiếm tỷ lệ $6,7 \%$ và $7,0 \%$. Các yếu tố liên quan đến nguy cơ trầm cảm có thể kể đến: hài lòng với ngoại hình, khó khăn về tài chính, tập thể dục, suy giảm sức khỏe bản thân hoặc là chấn thương ốm nặng, một người thân trong gia đình bị bệnh nặng, xung đột với bạn cùng phòng, điểm học không như mong đợi, thích nghi với phương pháp học tại trường đại học

\section{TÀI LIẸU THAM KHẢO}

1. Sena T. Manual Diagnóstico e Estatístico de Transtornos Mentais - DSM-5, estatísticas e ciências humanas: inflexões sobre normalizações e normatizações. Revista Internacional Interdisciplinar INTERthesis. 2014;11:96. doi: $10.5007 / 1807-1384.2014 v 11 n 2 p 96$

2. \&quot;Depression: let's talk\&quot; says $\mathrm{WHO}$, as depression tops list of causes of ill health. $\begin{array}{lll}\text { Accessed November } & 19,1 .\end{array}$ https://www.who.int/news/item/30-03-2017-depression-let-s-talk-says-who-as-depression-topslist-of-causes-of-ill-health

3. Shah P, Sapkota A, Chhetri A. Depression, Anxiety and Stress among First-year Medical Students in a Tertiary Care Hospital: A Descriptive Cross-sectional Study. JNMA J Nepal Med Assoc. 2021;59(236):346-349. doi:10.31729/jnma.6420

4. Nguyển Hoàng Nguyên. Trâm cảm, lo âu và stress ở sinh viên hệ bác sĩ trường Đại học Y Hà Nội năm học 2018-2019 và một số yếu tố liên quan.

5. Do QD, Tasanapradit P. Depression and Stress among the First Year Students in University of Medicine and Pharmacy, Hochiminh city, Vietnam. Journal of Health Research. 2008;22(Suppl.):1-4.

6. Nguyến Thị Bích Liên. Nguy cơ trâm cảm ở một sổ khối sinh viên đa khoa trướng Đại hoc Y Hà Nội năm học 2010-2011 và một số yếu tố liển quan.

7. Pham T, Bui L, Nguyen A, et al. The prevalence of depression and associated risk factors among medical students: An untold story in Vietnam. PLoS One. 2019;14(8):e0221432. doi:10.1371/ journal.pone.0221432

8. Soares LC, Batista RFL, Cardoso VC, et al. Body image dissatisfaction and symptoms of depression disorder in adolescents. Braz J Med Biol Res. 2020;54(1):e10397. doi:10.1590/1414431X202010397 